\title{
Proibicionismo e poder regulatório: uma pesquisa documental sobre o processo administrativo de classificação das drogas
}

\author{
Prohibition and regulatory authority: a documental research about drugs categorizing \\ administrative process
}

Prohibicionismo y potestad reglamentaria: una investigación documental acerca del proceso administrativo de clasificación de las drogas

\author{
Milena Karla Soares ${ }^{1}$ \\ Cristina Maria Zackseski²
}

\begin{abstract}
RESUMO: Esse trabalho tem como objetivo mapear o processo decisório identificando atores e fundamentos da produção normativa regulatória no âmbito das políticas públicas sobre drogas, consubstanciadas na edição e atualizações da Portaria SVS/MS no 344/1998, que define as regras para substâncias de controle especial e substâncias proibidas no Brasil, e complementam o sentido da Lei 11.343/2006. Foi realizada uma pesquisa documental para elucidar os seguintes pontos: correspondência dos atos praticados pela ANVISA à necessidade de acompanhar as atualizações das listas das convenções internacionais sobre o tema; atores que tem iniciativa no processo de inclusão de substâncias; etapas do processo; utilização de instrumentos de participação social, transparência decisória e accountability; fontes consultadas para subsidiar a decisão e principais motivos relatados nos pareceres técnicos. Os resultados mostram que não há plena correspondência entre os parâmetros internacionais e a inclusão das substâncias nas listas de controle brasileiras e que o fundamento da proibição está mais relacionado a razões de segurança do que propriamente aos danos para a saúde, provavelmente devido à influência assimétrica de grupos de interesse no processo administrativo.
\end{abstract}

Palavras-chave: Drogas. Proibicionismo. Agências Reguladoras. Saúde Pública. Segurança pública.

ABSTRACT: This work aims to map the decision making process and identify actors and foundation of regulatory normative acts within public policy about drugs, consubstantiated with the edition and updates of Portaria SVS/MS no 344/1998, which defines rules to substances under special control and forbidden substances in Brazil, and complement the meaning of Law 11.343/2006. A documentary research was made to elucidate the following

\footnotetext{
1 Bacharel em Economia pela Faculdade de Economia, Administração e Contabilidade de Ribeirão Preto da Universidade de São Paulo (FEA-RP/USP). Bacharel em Direito pela Faculdade de Direito da Universidade de Brasília (FD/UnB). Técnica de Desenvolvimento e Administração do Instituto de Pesquisa Econômica Aplicada (Ipea). Brasília, DF. milenakarlasoares@gmail.com

2 Doutora em Estudos Comparados Sobre As Américas pela Universidade de Brasília (2006). Mestre em Direito pela Universidade Federal de Santa Catarina (1997). Graduada em Direito na Universidade Federal de Santa Maria (1993), Atualmente é Professora Adjunta da Faculdade de Direito da Universidade de Brasília (UnB), credenciada na pós-graduação para os cursos de Mestrado e Doutorado (2012). É Vice coordenadora do Núcleo de Estudos sobre Violência e Segurança (NEVIS/UnB) (2015). Professora convidada do Mestrado do Instituto Superior de Ciências Policiais e Segurança Interna de Portugal (2012). Líder do Grupo de Pesquisa Política Criminal (2007) e representante da Universidade de Brasília na Rede Eurolatinoamericana para Prevenção da Tortura e da Violência Institucional (2015). Email: cristinazbr@gmail.com.
} 
issues: compliance of the acts of National Agency for Sanitary Vigilance - ANVISA to the actualizations of the lists of the international conventions about the theme; actors who have initiative of the inclusion process of substances; steps of the process; use of social participation, decisional transparency and accountability mechanisms; consulted sources to subsidize the decision and main reasons related in the technical reports. The results shows that there's not total compliance to the international parameters with the inclusion of substances in the Brazilian controlling lists and that the prohibition is more related to public security reasons than health damages, probably due to asymmetric influence of interest groups in the administrative process.

Keywords: Drugs. Prohibition. Regulatory Agency. Public Health. Public Security.

RESUMEN: Este trabajo tiene como objetivo describir el proceso de toma de decisiones y identificar los actores y la fundamentación de la producción normativa reguladora ubicada en las políticas públicas de drogas, consagrados en la edición y actualiza la SVS / MS № 344/1998 por el que se establecen normas para el control de sustancias especiales y prohibidos en Brasil, y complementan el sentido de la Ley 11.343 / 2006. La investigación documental se llevó a cabo para aclarar los siguientes puntos: correspondencia de los actos realizados por la ANVISA a la necesidad de seguir las actualizaciones de la lista de los convenios internacionales en la materia; actores que tienen la iniciativa de incluir sustancias; las fases del proceso de inclusión de substancias; los instrumentos de participación social, transparencia y responsabilidad en la toma de decisiones; fuentes consultadas para apoyar la decisión y las razones principales reportados en los informes técnicos. Los resultados muestran que no existe plena correspondencia entre las normas internacionales y la inclusión de sustancias en las listas de control de Brasil, así que el motivo de la prohibición está más cerca de razones de seguridad que en realidad tiene que ver con los daños a la salud, probablemente debido a la influencia asimétrica de grupos de interés en el proceso administrativo.

Palabras-Ilave: Drogas. Prohibicionismo. Agencias Reguladoras. Salud Pública. Seguridad Pública.

\section{Introdução}

A necessidade ou não da proibição das drogas é um tema que provoca fortes reações no Brasil. No entanto, o debate que se estabelece em torno do problema é, geralmente, de cunho emocional, sendo pouco observados componentes técnicos e científicos na sustentação dos argumentos apresentados.

No Brasil a criminalização de condutas relacionadas à determinadas substâncias, genericamente referidas por "drogas" está contida na Lei n. 11.343/2006, mas as substâncias proibidas estão listadas na Portaria n. 344/1998, da Secretaria de Vigilância Sanitária do Ministério da Saúde (1), que define as regras para substâncias de controle especial e substâncias proibidas e complementa o sentido da atual lei de drogas. 
Em outubro de 2013 o juiz de direito substituto Frederico Ernesto Cardoso Maciel, da 4" Vara de Entorpecentes do Distrito Federal, absolveu réu acusado de trazer porções de maconha consigo para fins de difusão ilícita em complexo penitenciário, e a maconha, ou cannabis sativa, está entre as substâncias proibidas por conter THC (Tetrahidrocanabinol), que é classificada como substância psicotrópica e consta da Lista F2 da referida Portaria. A conduta estava corretamente tipificada, os fatos eram incontroversos e estavam presentes materialidade e autoria. O fundamento da absolvição foi a ilegalidade e inconstitucionalidade da Portaria:

No caso, o Ministério da Saúde, por meio da portaria 344/1998, com o objetivo de complementar a norma do art. 33, caput, da lei 11343/06, estabeleceu um vastíssimo rol de substâncias sujeitas a controle e, sem qualquer justificativa constante na referida portaria, na lista $F$, proibiu, entre outras, O THC.

$\mathrm{O}$ ato administrativo, em especial o discricionário restritivo de direitos, diante dos direitos e garantias fundamentais e também dos princípios constitucionais contidos no art. 37 da Constituição da República devem ser devidamente motivados, sob pena de permitir ao Administrador atuar de forma arbitrária e de acordo com a sua própria vontade ao invés da vontade da lei.

A portaria 344/98, indubitavelmente um ato administrativo que restringe direitos, carece de qualquer motivação por parte do Estado e não justifica os motivos pelos quais incluem a restrição de uso e comércio de várias substâncias, em especial algumas contidas na lista $\mathrm{F}$, como o $\mathrm{THC}^{3}$ o que, de plano, demonstra a ilegalidade do ato administrativo.

Sem motivação, tal norma fica incapaz de poder complementar a norma penal do art. 33, caput, da lei 11343/06. [...] (2)

A referida portaria foi considerada ilegal pela ausência de motivação e justificativa, e inconstitucional por violar os princípios da igualdade, liberdade e dignidade humana. Para o juiz, há incoerência no fato de algumas substâncias entorpecentes, como álcool e tabaco, serem permitidos, vendidos e largamente utilizados adorados pela população, enquanto outras substâncias de mesma natureza têm seu uso recreativo proibido.

Posteriormente a sentença foi reformada pelo Tribunal de Justiça do Distrito Federal, que declarou inexistir ilegalidade e inconstitucionalidade. O juiz titular da vara, Aimar Neres de Matos, criticou publicamente a decisão no jornal O Globo, afirmando que a decisão não tem respaldo da $4^{\text {a }}$ Vara de entorpecentes e não mostra uma tendência de mudança de pensamento do poder judiciário (3).

\footnotetext{
${ }^{3}$ Tetrahidrocanabinol, derivado da planta cannabis.
} 
Independentemente de a Portaria SVS/MS n 344/1998 ser considerada legal ou ilegal, constitucional ou inconstitucional, o que a decisão do juiz Cardoso Maciel deixou evidente é a ausência de clareza e transparência perante a sociedade quanto aos motivos que embasam os atos de regulação.

Dados do Ministério da Justiça (4) apontam que aproximadamente $35,1 \%{ }^{4}$ das pessoas presas respondem por crimes de tráfico de drogas. Considerando-se um sistema prisional superlotado ${ }^{5}$, em que ocorrem inúmeras violações aos direitos humanos e que demanda a cada dia um aporte maior de recursos orçamentários e financeiros, é preciso sublinhar que as consequências dos atos regulatórios praticados no âmbito da política sobre drogas não são nada desprezíveis. Por esse motivo não é aceitável que pairem dúvidas quanto à legalidade e constitucionalidade desses atos, cuja forma, motivação e conteúdo merecem ser apresentados à sociedade.

A investigação realizada nesse trabalho insere-se nesse contexto. Trata-se de um trabalho empírico cujo objetivo geral é mapear o processo decisório identificando atores e fundamentos envolvidos na produção normativa de classificação de substâncias no âmbito de políticas sobre drogas, desde a edição da Portaria SVS/MS nํ 344, de 12 de maio de 1998, até a atualização pela Resolução da Diretoria Colegiada da ANVISA $^{6}$ n$^{0}$ 44, de 08 de outubro de 2015.

Tendo em vista que a existência de convenções de direito internacional sobre a matéria, inicialmente foi realizada uma análise comparativa entre as listas de substâncias proscritas nacionais ${ }^{7}$ e as listas de substâncias sob controle internacionais ${ }^{8}$, com o intuito de verificar a existência de alinhamento ou limitação do direito regulatório nacional às disposições das convenções. Uma vez identificadas as substâncias para as quais não havia correspondência nas listas internacionais, procedeu-se à análise documental dos

\footnotetext{
${ }^{4}$ Consideradas apenas as mulheres, o número é espantoso: $63 \%$ delas respondem por crime de tráfico de drogas. Para os homens, esse percentual é de $25 \%$. Em alguns estados o número de pessoas que respondem por tráfico de drogas chega próximo ou supera a metade: no Amazonas 51,8\%, em Mato Grosso 51,3\%, no Rio Grande do Sul 49,7\%, em Santa Catarina 48\% e no Espírito Santo 44\%. (4)

${ }^{5} \mathrm{Em}$ junho de 2014, havia 607.731 pessoas em estabelecimentos prisionais no país. Estabelecimentos superlotados com uma taxa de ocupação de 161\%, para uma disponibilidade de 376.669 vagas do sistema. Se a trajetória da taxa de encarceramento observada nos anos anteriores for mantida o cenário para o sistema prisional não é nada animador. A taxa de aprisionamento para cada 100 mil habitantes cresceu $136 \%$ entre 1995 e 2010 , e em junho de 2014 era de 300 presos para cada 100 mil habitantes. (4)

${ }^{6}$ Agência Nacional de Vigilância Sanitária.

7 Listas E, F1, F2, F3 da Portaria SVS/MS no 344/1998, que serão detalhadas ao longo do texto.

8 Yellow, Green e Red Lists, decorrentes, respectivamente, das Convenções de 1961, 1971 e 1988, que serão detalhadas ao longo do texto.
} 


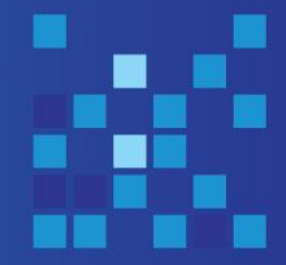

processos administrativos que resultaram em sua inclusão. O método de análise documental trata da dimensão burocrática da realidade, consubstanciada em documentos e própria da administração pública (5), e por esse motivo foi escolhido para abordar o objeto de produção normativa regulatória por uma autarquia da administração pública federal.

\section{Fundamento jurídico-positivo do poder regulador para classificação de substâncias}

No Brasil, a criminalização da produção, comércio e uso de drogas foi feita por uma norma penal em branco, pois a tipificação da conduta depende de definições que estão em outra lei (formal ou material). Para Zaffaroni e Pierangeli (6), a lei penal em branco não cria maiores problemas quando a fonte normativa a que remete é outra lei emanada do Congresso Nacional. Caso a lei penal faça remissão a uma lei emanada de outro poder (poder legislativo estadual ou municipal, ou ainda o poder executivo de qualquer uma das esferas), os autores fazem a seguinte ressalva:

O Poder que completa a lei em branco deve ter o cuidado de respeitar a natureza das coisas porque, do contrário, através de tal recurso pode ser mascarada uma delegação de competências legislativas penais. Assim, por exemplo, o Executivo não pode incluir o café na lista de substâncias entorpecentes, como tampouco incluir o vinho. Nem mesmo poderia incluir um rifle de ar comprimido entre as armas de guerra. (6)

Atualmente, a norma penal que trata do assunto é a Lei no 11.343 , de 26 de agosto de 2006 (7), que, em seus artigos 1ํㅡ e 66, apresentam o problema do qual estamos tratando:

Art. 1 Esta Lei institui o Sistema Nacional de Políticas Públicas sobre Drogas - Sisnad; prescreve medidas para prevenção do uso indevido, atenção e reinserção social de usuários e dependentes de drogas; estabelece normas para repressão à produção não autorizada e ao tráfico ilícito de drogas e define crimes.

Parágrafo único. Para fins desta Lei, consideram-se como drogas as substâncias ou os produtos capazes de causar dependência, assim especificados em lei ou relacionados em listas atualizadas periodicamente pelo Poder Executivo da União.

[...]

Art. 66. Para fins do disposto no parágrafo único do art. 1ํ desta Lei, até que seja atualizada a terminologia da lista mencionada no preceito, denominam-se drogas substâncias entorpecentes, psicotrópicas, precursoras e outras sob. 
A lei foi regulamentada pelo Decreto Presidencial oㅜ 5.912, de 27 de setembro de 2006 (8), que estruturou o Sistema Nacional de Políticas Públicas sobre Drogas - SISNAD, cujo órgão normativo e de deliberação coletiva é o Conselho Nacional de Políticas sobre Drogas - CONAD (antigo Conselho Nacional Antidrogas), que conta com a Secretaria Nacional de Políticas sobre Drogas - SENAD ${ }^{9}$ na qualidade de secretaria executiva. Ambos os órgãos (CONAD e SENAD) atualmente vinculam-se ao Ministério da Justiça. Há previsão de dois assentos para o Ministério da Saúde no CONAD, sendo um deles destinado à Agência Nacional de Vigilância Sanitária - ANVISA.

A definição do rol de substâncias definidas como "drogas" e complementação do sentido da norma penal é competência específica do Ministério da Saúde ${ }^{10}$ e tem sido exercida por meio da ANVISA ${ }^{11}$, autarquia especial que lhe é vinculada, instituída pela Lei № 9.782, de 26 de janeiro de 1999 (9), regulamentada pelo Decreto $n=3.029$, de 16 de abril de 1999 (10), que atua com a finalidade de promover a proteção da saúde da população, por intermédio do controle sanitário da produção e da comercialização de produtos e serviços submetidos à vigilância sanitária, inclusive dos ambientes, dos processos, dos insumos e das tecnologias a eles relacionados, bem como o controle de portos, aeroportos e fronteiras.

No Regimento Interno aprovado pela Resolução da Diretoria Colegiada ํㅜㄹ, de 21 de julho de 2015 (11), a competência para "elaborar e manter atualizadas as listas de substâncias entorpecentes, psicotrópicas, precursoras e outras sujeitas a controle especial", bem como para "elaborar e consolidar dados sobre substâncias entorpecentes, psicotrópicas e precursoras, em cumprimento aos acordos internacionais ratificadas pelo Brasil frente à Organização das Nações Unidas, Organização dos Estados Americanos, MERCOSUL e outros organismos internacionais", foi atribuída à Coordenação de Produtos Controlados (CPCON), subordinada à Gerência Geral de Fiscalização de Produtos Sujeitos à Vigilância Sanitária da Superintendência de Fiscalização, Controle e Monitoramento.

\footnotetext{
${ }^{9}$ Antiga Secretaria Nacional Antidrogas.

10 Art. 14, I, "a" e "b": "publicar listas atualizadas periodicamente das substâncias ou produtos capazes de causar dependência" e "baixar instruções de caráter geral ou específico sobre limitação, fiscalização e controle da produção, do comércio e do uso das drogas" (7)

${ }^{11}$ Art. 14, Parágrafo Único: "As competências específicas dos Ministérios e órgãos de que trata este artigo se estendem, quando for o caso, aos órgãos e entidades que lhes sejam vinculados” (7)
} 
O Regimento Interno refere-se às listas anexas à Portaria SVS/MS no 344/1998 (1) que classifica as substâncias em 15 listas, sendo de especial interesse para esse estudo as listas $\mathrm{E}$ (plantas que podem originar substâncias entorpecentes e/ou psicotrópicas), F1 (substâncias entorpecentes) e F2 (substâncias psicotrópicas) e F3 (substâncias precursoras) de uso proscrito no Brasil. As atualizações dessas listas ocorrem por resolução da Diretoria Colegiada da ANVISA após análise e parecer da CPCON e demais áreas técnicas envolvidas.

\section{O processo de classificação de drogas no direito internacional}

Apesar de a observação empírica do processo de atualização das listas das convenções internacionais não ser objeto desse trabalho, considera-se pertinente apresentar quais as regras desse processo, tendo em vista que a Organização das Nações Unidas (ONU) vem sendo uma das principais instâncias multilaterais para promover e assegurar o aumento do rol de drogas controladas, principalmente, as substâncias psicotrópicas, por meio das convenções (12).

Com relação aos atores, a ONU conta com o Conselho Econômico e Social (ECOSOC), composto por 54 membros eleitos pela Assembleia Geral, e em cujo âmbito há duas instâncias especializadas de interesse para esse trabalho: a Comissão de Narcóticos (CND) e a Organização Mundial de Saúde (OMS). São relevantes também o Escritório das Nações Unidas sobre Drogas e Crimes (UNODC), braço operacional da CND, e a Junta Internacional de Fiscalização de Entorpecentes (JIFE), que recebe e compila os relatórios e estatísticas que devem ser apresentados periodicamente pelos países para monitorar a implementação das convenções.

A Convenção Única sobre Entorpecentes de 1961 (13), em seu Artigo 36, impõe aos signatários o compromisso de punir as condutas contrárias ao texto da convenção, sendo que as ofensas consideradas mais graves devem ser punidas com privação de liberdade e os usuários de drogas devem ser submetidos a tratamento. Anexa a essa Convenção está a chamada Yellow List, contendo a relação de substâncias sujeitas a controle especial e/ou proibição. A lista pode ser atualizada por iniciativa da OMS ou das partes, seguindo-se o procedimento descrito no Artigo 3. A atualização compete à CND, podendo ser revisada 


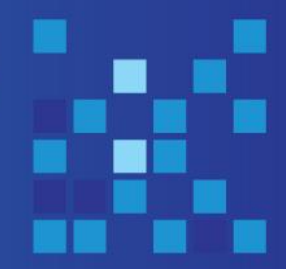

pelo ECOSOC. As decisões da CND passam a vigorar a partir do momento em que é recebida a respectiva comunicação pela parte.

A Convenção sobre Substâncias Psicotrópicas de 1971 (14) é complementar à Convenção de 1961, criando mais uma lista de substâncias sobre controle, a chamada Green List. O procedimento para atualização da Green List (Convenção de 1971) é semelhante ao procedimento de atualização da Yellow List (Convenção de 1961). A solicitação de atualização pode partir da OMS ou de uma das partes. A atualização é feita pela CND, podendo ser revisada pelo ECOSOC. As decisões da CND passam a vigorar 180 dias após o recebimento da comunicação pela parte. A Convenção de 1971 também atribui à JIFE as funções de monitoramento e fiscalização, recebimento de estatísticas dos países e produção de relatórios.

É interessante observar que o Artigo 2 da Convenção de 1971 elenca critérios ${ }^{12}$ a serem observados pela OMS em sua comunicação à CND sobre a existência de uma nova substância a ser incluída na lista. As informações fornecidas pela OMS devem ser consideradas determinantes do ponto de vista médico-científico. Na sequência, a CND deve analisar a questão sobre o ponto de vista econômico, social, legal, administrativo e outros aspectos relevantes, e então decidir sobre a inclusão na lista.

A Convenção Contra o Tráfico llícito de Entorpecentes e Substâncias Psicotrópicas de 1988 (15), por sua vez, tem como foco a criação de mecanismos para combate ao tráfico ilícito internacional. Trata, por exemplo, de jurisdição, da criminalização da "lavagem de dinheiro", confisco de bens, extradição e jurisdição. Essa convenção cria a chamada Red List, contendo rol de substâncias utilizadas na fabricação ilícita de entorpecentes e de substâncias psicotrópicas, e que por esse motivo devem sujeitar-se a controle internacional.

No que se refere ao procedimento de atualização da Red List, há uma diferença comparativamente às convenções de 1961 e 1971: a JIFE substitui a OMS quanto à notificação da necessidade de alterações ao Secretário Geral das Nações Unidas. Desse

\footnotetext{
12 If the World Health Organization finds: a) That the substance has the capacity to produce i) 1) A state of dependence, and 2) Central nervous system stimulation or depression, resulting in hallucinations or disturbances in motor function or thinking or behavior or perception or mood, or ii) Similar abuse and similar ill effects as a substance in Schedule I, II, III or IV, and b) That there is sufficient evidence that the substance is being or is likely to be abused so as to constitute a public health and social problem warranting the placing of the substance under international control [...]. (Artigo 2 da Convenção sobre Substâncias Psicotrópicas de 1971) (13)
} 


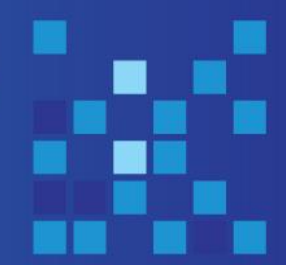

modo, as alterações da Red List podem ser solicitadas pela JIFE ou por uma das partes. A alteração é competência da CND, do mesmo modo como ocorre com as demais listas (Yellow e Green Lists).

O Artigo 12 da Convenção de 1988 elenca os critérios $^{13}$ a serem levados em conta pela JIFE em sua comunicação à CND. Os apontamentos da JIFE são considerados determinantes do ponto de vista científico. Após considerar outros fatores relevantes, a CND decide sobre a alteração da lista.

Percebe-se, portanto, que as convenções de direito internacional que tratam da matéria estabelecem procedimentos, atores e responsabilidades para iniciativa e deliberação sobre a atualização das listas de substâncias controladas ou proibidas, bem como os critérios a serem levados em consideração pelas instâncias técnicas (JIFE e OMS), que elaboram os pareceres para serem apreciados pelos conselhos deliberativos (CND e ECOSOC).

\section{Autonomia dos países e discricionariedade do ato regulatório}

Em decorrência da ratificação das convenções internacionais sobre o tema, o Brasil abriu mão de parte de sua autonomia ${ }^{14}$ em matéria de política de drogas ao se obrigar a aderir as alterações que forem introduzidas pelos organismos internacionais, com a ressalva de que há permissão para que os países adotem medidas mais estritas ou rigorosas, conforme dispositivo da Convenção de 1971, Artigo 24:

As Partes poderão adotar medidas mais estritas ou rigorosas que as previstas na presente Convenção se, a seu juízo, tais medidas são convenientes ou necessárias para impedir ou eliminar o tráfico ilícito (14)

Portanto, da perspectiva do direito internacional, verificamos que os países gozam de certo nível de autonomia, apesar de limitada pois somente pode ser exercida no sentido de

\footnotetext{
13 If the Board, taking into account the extent, importance and diversity of the licit use of the substance, and the possibility and ease of using alternate substances both for licit purposes and for the illicit manufacture of narcotic drugs or psychotropic substances, finds: a) That the substance is frequently used in the illicit manufacture of a narcotic drug or psychotropic substance; b) That the volume and extent of the illicit manufacture of a narcotic drug or psychotropic substance creates serious public health or social problems, so as to warrant international action [...]. (Artigo 12 da Convenção contra o Tráfico llícito de Entorpecentes e Substâncias Psicotrópicas de 1988) (14)

${ }_{14}$ Etimologicamente, autonomia designa o poder de estabelecer as próprias regras, do grego autos (por si mesmo) e nomos (normas, regras).
} 


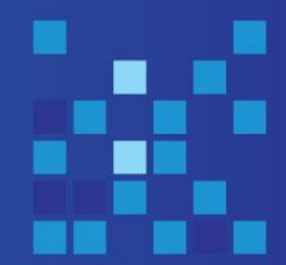

maior rigor. Nesse sentido, a literatura consultada demonstra que na história recente não houve pleno alinhamento funcional entre a política brasileira e as recomendações externas (12), como por exemplo o tratamento dado à ayahuasca ${ }^{15}$ durante a década de 1980 , incluída pelo Ministério da Saúde na lista de produtos proscritos apesar de não se encontrar sob controle internacional (16).

Posteriormente a ayahuasca foi retirada da lista por determinação do antigo Conselho Federal de Entorpecentes (CONFEN). Nesse sentido é esclarecedor o relato de Técio Lins e Silva, que presidiu o conselho entre 1985 e 1987, conforme documentado por Labate (16):

[...] o Delegado queria prender. Está na lei: é tráfico [...]. E nós tomamos uma deliberação que foi a mais importante de retirar o chá da lista do DIMED. A diretora do DIMED compreendeu [...], tudo indicava que o uso no ritual tinha seu próprio controle desde os tempos dos Incas. Montamos um grupo de trabalho [...]. Só que isso nos custou uma oposição fantástica. (16)

$\mathrm{Na}$ perspectiva do Direito Administrativo, a discussão está em saber se 0 ato praticado pela ANVISA é vinculado ${ }^{16}$ ou discricionário ${ }^{17}$. Será vinculado se adstrito aos parâmetros internacionais ou a outros parâmetros porventura existentes em norma interna. Será discricionário se houver liberdade de escolha para sua realização, a partir de um juízo de conveniência e oportunidade (17). Tendo em vista que no ordenamento jurídico interno não há parâmetros para a classificação e proibição de substâncias, quaisquer alterações que extrapolem o conteúdo das convenções internacionais serão discricionárias.

Com a análise empírica desse trabalho foi possível verificar que o padrão de descolamento entre a política brasileira e a política internacional, observado na década de 1980 (12) (16), se manteve na atuação da agência reguladora a partir de 1998.

\section{Agências reguladoras, accountability e transparência}

\footnotetext{
${ }^{15}$ A banisteriopsis caapi (ayahuasca, também referida como "daime") é uma planta utilizada tradicionalmente em rituais religiosos de tribos indígenas da Amazônia e passou a ser adotada nos rituais por algumas religiões sincréticas urbanas que surgiram a partir do início do século XX. A ayahuasca tem propriedades alucinógenas pela presença da substância DMT (N,N-dimetiltriptamina). Embora a substância DMT faça parte do rol de substâncias sob controle internacional da Green List da Convenção de 1971, a planta em si não está sob controle internacional (15).

${ }^{16}$ Atos vinculados ou regrados são aqueles para os quais a lei estabelece os requisitos e condições de sua realização (17)

17 Atos discricionários são os que a Administração pode praticar com liberdade de escolha de seu conteúdo, de seu destinatário, de sua conveniência, de sua oportunidade e de seu modo de realização (17)
} 
As agências reguladoras foram criadas no Brasil durante a década de 1990, imitando o modelo norte-americano. Instituições independentes do Executivo, por vezes rotuladas de "quarto poder", cuja legitimidade estaria fundada na expertise e conhecimento técnico, são dotadas de competências "quase legislativas e quase jurisdicionais" nas matérias de direito regulatório setorial que lhe são pertinentes (18).

A prevalência do conhecimento técnico é desejável, mas ao mesmo tempo dificulta o escrutínio do público em geral. Os processos decisórios em regulação frequentemente envolvem questões políticas delicadas e controvertidas, entretanto os decisores não estão imbuídos de legitimidade democrática: são tecnocratas julgados aptos por possuírem ampla expertise, mas na verdade tomam decisões e fazem escolhas baseadas em seus valores (19).

Por esse motivo, a teoria da public choice aponta para o risco de que a agência seja cooptada por grupos de interesse (empresas reguladas, governo, congressistas), corrompendo os resultados e objetivos finais desejáveis do ponto de vista de maximização do bem-estar social. Para Souza (20) essa corrente teórica desconfia da capacidade dos mecanismos políticos de decisão, devido à prevalência do autointeresse, informação incompleta, racionalidade limitada e captura das agências governamentais por interesses particularistas.

Por outro lado, a teoria jurídico-institucional da regulação (ou teoria do processo administrativo regulatório) (18) prevê que é possível que o processo de tomada de decisão da agência beneficie o interesse público, afastando o indesejável desequilíbrio de influência de grupos de interesse, desde que atendidos alguns requisitos: Em primeiro lugar os procedimentos administrativos devem estar em conformidade com os princípios constitucionais administrativos, conduzido de forma transparente e oportunizando participação social e críticas de quaisquer interessados para ajustes e melhoria no conteúdo da regulamentação. Além disso, deve haver neutralidade do processo administrativo, que pressupõe imparcialidade do tomador de decisão, e deve ser observado o ambiente jurídico-institucional administrativo, que implica necessária estabilidade profissional, incentivos à defesa do interesse público, controle externo e interno, entre outras medidas (18).

Com relação ao requisito de procedimento administrativo, a adoção de mecanismos de accountability vertical e horizontal, transparência pública e participação cidadã tornam- 
se essenciais para promoção do interesse público. Cruz (19) cita oito instrumentos postos à disposição da ANVISA e que contribuem para essa finalidade: (i) contrato de gestão firmado com o Ministério da Saúde, em que se estabelecem objetivos e metas de desempenho; (ii) conselho consultivo, órgão colegiado composto por representantes da administração pública, sociedade civil e comunidade científica, responsável pelo acompanhamento das atividades e apreciação dos requerimentos da agência; (iii) ouvidoria, canal de comunicação para o recebimento de pedidos de informações, elogios, sugestões, denúncias ou queixas; (iv) audiências públicas abertas a toda a população, para discussão de assuntos de maior destaque; (v) consultas públicas realizadas antes da publicação de uma nova norma, resolução ou regulamento, em que a população se manifesta em fórum virtual de discussão; (vi) agenda regulatória elaborada e divulgada anualmente, com o intuito de promover a previsibilidade e transparência da atuação regulatória; (vii) câmaras setoriais, de natureza consultiva, formada por representantes da sociedade civil, setor produtivo e governo; (viii) câmaras técnicas, de natureza consultiva, formada por membros da comunidade científica.

$\mathrm{Na}$ análise empírica dos processos de classificação de substâncias foi observado se a ANVISA utilizou-se desses instrumentos para subsidiar a decisão da diretoria colegiada, em especial, os instrumentos de audiências públicas, consultas públicas, câmaras setoriais e câmaras técnicas, que mais se adequam à característica processual da decisão.

\section{Análise empírica dos processos de classificação de drogas}

$\mathrm{Na}$ análise empírica que se segue, buscou-se elucidar os seguintes pontos:

1. Os atos praticados pela ANVISA estão vinculados à necessidade de acompanhar as atualizações das listas de substâncias sob controle internacional?

2. Para os casos em que não haja coincidência entre as listas: de quem é a iniciativa do processo de inclusão? Quais as etapas do processo? O processo contempla instrumentos de participação social, transparência decisória e accountability? Quais são as fontes consultadas para subsidiar a decisão? Quais os principais motivos relatados nos pareceres técnicos?

Consideradas em conjunto, as listas E, F1, F2 e F3, na Portaria SVS/MS № 344/1998, conforme redação originalmente no Diário Oficial da União, em 15 de maio de 1998, 
contavam com 50 substâncias/plantas de uso proscrito no Brasil. Desde então houve 70 inclusões e 1 exclusão nesse rol.

Até a publicação da Resolução de Diretoria Colegiada ํo 44, de 08 de outubro de 2015, o rol contava com 119 substâncias/plantas, das quais 53 não guardam correspondência imediata com os itens das listas internacionais ${ }^{18}$. Percebe-se, portanto, que os atos da ANVISA não estão adstritos ao conteúdo das convenções de direito internacional sobre a matéria, confirmando a hipótese de discricionariedade de exercício do poder regulatório.

Tabela 1. Inclusões de substâncias e plantas na Portaria SVS/MS no 344/1998, até a Resolução de Diretoria Colegiada no 44, de 08 de outubro de 2015.

\begin{tabular}{cccccc}
\hline Lista & $\begin{array}{c}\text { Número de } \\
\text { itens da } \\
\text { Portaria } \\
\text { SVS/MS } \\
\text { Original DOU } \\
\text { 15mai1998 }\end{array}$ & $\begin{array}{c}\text { Número } \\
\text { de itens } \\
\text { excluído } \\
\text { s }\end{array}$ & $\begin{array}{c}\text { Número } \\
\text { de itens } \\
\text { incluído } \\
\text { s }\end{array}$ & $\begin{array}{c}\text { Número } \\
\text { de itens } \\
\text { na } \\
\text { versão } \\
\text { vigente }\end{array}$ & $\begin{array}{c}\text { Número de itens } \\
\text { sem } \\
\text { correspondência } \\
\text { com as listas } \\
\text { internacionais }\end{array}$ \\
\hline $\begin{array}{c}\text { E - Plantas que } \\
\text { podem originar }\end{array}$ & 6 & 0 & 2 & 8 & 5 \\
$\begin{array}{c}\text { F1 - Substâncias } \\
\text { entorpecentes }\end{array}$ & 15 & 0 & 6 & 21 & 0 \\
$\begin{array}{c}\text { F2 - Substâncias } \\
\text { psicotrópicas }\end{array}$ & 29 & 1 & 61 & 89 & 48 \\
$\begin{array}{c}\text { F3 - Substâncias } \\
\text { precursoras }\end{array}$ & 0 & 0 & 1 & 1 & 0 \\
\hline Total & 50 & 1 & 70 & 119 & 53 \\
\hline
\end{tabular}

Fonte: elaboração própria

Pretendia-se analisar os processos de inclusão desses 53 itens sem correspondência nas listas internacionais. Os processos foram solicitados à ANVISA, com fundamento na

\footnotetext{
${ }^{18}$ A análise consistiu em verificar quais das substâncias das listas E, F1, F2 e F3 da Portaria SVS/MS no 344/1998 - atualizada até a Resolução de Diretoria Colegiada № 44, de 08 de outubro de 2015, não constavam das versões mais atualizadas das listas das convenções internacionais ( Yellow List - 53" edição,

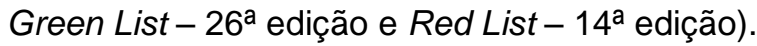


Lei de Acesso à Informação (21). Alguns destes não foram encontrados, considerados como "informação inexistente", sendo 3 substâncias da lista F2 e todas as 5 plantas da lista E. Portanto, foi possível analisar apenas os processos de inclusão de 45 substâncias da lista F2.

Quanto à iniciativa, verifica-se a prevalência da própria ANVISA e de solicitações do Departamento de Polícia Federal (DPF/MJ), que tem colaborado de forma estreita para garantir que a lista se mantenha atualizada, mediante comunicação sobre novas substâncias apreendidas, conforme trecho extraído dos pareceres técnicos juntados aos processos:

Com o intuito de coibir o comércio clandestino de novas substâncias psicotrópicas que aparecem no mercado ilícito, o Departamento de Polícia Federal tem colaborado buscando atualizar as listas de produtos controlados e proscritos das Resoluções de Diretoria Colegiada ${ }^{19}$.

Na maior parte das inclusões por iniciativa ex officio da ANVISA há uma relação com as comunicações recebidas da DPF/MJ. Por exemplo, a DPF/MJ informou sobre a apreensão das substâncias 25I-NBOMe e 25C-NBOMe em território brasileiro, sugerindo sua inclusão na lista F2. A ANVISA endossou a sugestão, e decidiu incluir outras 8 substâncias derivadas na lista.

Nos 3 processos iniciados por solicitação do Ministério Público de São Paulo, este requisitou a inclusão das substâncias nas respectivas listas no prazo de 48 horas. Para o membro do MP, o fato de não haver previsão da Portaria no 344/1998 proporcionava impunidade, pois a substância foi encontrada em território nacional, sendo que em outros países é proibida.

Tabela 2. Número de processos de inclusão de substância por autoria

19 Parecer Técnico no 003/2013-SEDQ/DIREN/CGPRE/DCOR do DPF/MJ. 


\begin{tabular}{cc}
\hline Ator & Número de iniciativas \\
\hline ANVISA & 22 \\
DPF/MJ ${ }^{20}$ & 20 \\
DPF/MJ e MP/SP & 1 \\
MP/SP & 2 \\
\hline Total & 45 \\
\hline
\end{tabular}

Fonte: elaboração própria

Em geral, os processos tiveram as seguintes etapas: (i) recebimento da solicitação de inclusão (nos casos em que houve solicitação externa); (ii) análise e parecer pela Coordenação de Produtos Controlados; (iii) análise e parecer pela Diretoria de Regulação Sanitária; (iv) deliberação pela Diretoria Colegiada.

Observou-se limitada utilização de instrumentos de accountability, transparência e participação social, restringindo-se à divulgação anual da agenda regulatória e à publicação das resoluções de diretoria colegiada. Não foram utilizados instrumentos que propiciassem a ampliação da participação e transparência durante o processo decisório, tais como consultas ou audiências públicas, tampouco consultas às câmaras setoriais ou técnicas.

Em todos os casos analisados, as substâncias incluídas foram consideradas potenciais drogas de abuso por possuírem efeitos psicotrópicos e/ou estrutura química semelhantes a outras drogas. Foram 17 canabinóides sintéticos que mimetizam o efeito do THC (componente da cannabis), 16 substâncias alucinógenas comparáveis ao LSD, 6 substâncias consideradas substitutas ao MDMA (ecstasy): 3 substâncias similares às anfetaminas e 5 comparáveis a outras substâncias psicotrópicas controladas ou proibidas.

$\mathrm{Na}$ elaboração dos pareceres técnicos foram utilizadas principalmente referências de literatura médica especializada, publicações do Drug Enforcement Administration (agência governamental de controle de narcóticos dos Estados Unidos), do Escritório das Nações Unidas para Drogas e Crimes - UNODC, da Junta Internacional de Fiscalização de Entorpecentes, do sistema Early Warning Advisory (EWA) da UNODC, e relatos de 


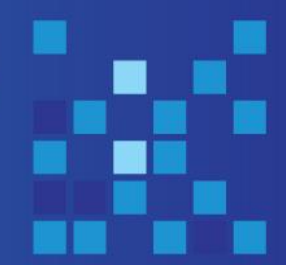

usuários disponíveis no portal Erowid na Internet ${ }^{22}$, fontes nas quais se buscam informações sobre a toxicidade, potencial de abuso e adicção, oferta no mercado ilegal e aplicação industrial lícita.

A similaridade de estrutura química e de efeitos psicotrópicos com outras drogas proibidas é um dos principais fundamentos da inclusão de novas substâncias na lista, as chamadas Novas Substâncias Psicotrópicas (NSP). Os motivos relacionados a características químicas e farmacêuticas, não foram objeto de escrutínio nessa análise devido à limitação de conhecimento técnico sobre o assunto. No entanto observou-se que em 15 dos casos analisados os pareceres técnicos apontavam insuficiente conhecimento técnico sobre a substância, quanto aos seus efeitos adversos à saúde, toxicidade e dependência. A despeito disso, a substância foi incluída na lista. Parece haver uma presunção que pesa em favor do proibicionismo: na dúvida, proíbe-se.

Tampouco parece haver tempo para realização de estudos e pesquisas mais aprofundados. Parte-se do pressuposto de que a nova droga é ilegal (burla a legislação vigente) mesmo antes de ser incluída na lista da agência regulatória, não havendo necessidade de se investigar em profundidade seus efeitos:

Nos anos 90 ocorreu o aparecimento de novas drogas sintéticas e a popularização das designer drugs. Essas últimas têm como características essenciais o fato de terem sido modificadas em laboratórios com intuito de potencializar, criar efeitos psicoativos ou evitar efeitos indesejáveis, além de burlar a legislação vigente. Nesse escopo, esses compostos são produzidos baseados na premissa de ressintetizar drogas já existentes e que obtenham as mesmas ações psicotrópicas, com moléculas quimicamente diferentes da droga original. Como as estruturas moleculares das novas drogas são alteradas, essas não são definidas como proscritas em legislações pátrias ${ }^{23}$.

A busca pela celeridade na atualização da lista de substâncias proscritas é devida, em certa medida, ao contexto e ideologia de guerra às drogas, que leva à necessidade de minar as fontes de rendas das organizações criminosas. O Departamento de Polícia Federal está imbuído nessa missão, e, portanto, é compreensível que a preocupação desse departamento esteja mais relacionada ao desmonte do narcotráfico do que com a saúde, liberdade e dignidade do consumidor de psicotrópicos. Em 25 dos casos analisados

\footnotetext{
22 Erowid é uma organização que tem como objetivo documentar as experiências humanas com psicoativos (www.erowid.org).

${ }^{23}$ Parecer Técnico no 003/2013-SEDQ/DIREN/CGPRE/DCOR do DPF/MJ
} 
aponta-se explicitamente o "combate ao narcotráfico" como fundamento para a inclusão da substância na lista, como exemplificam os trechos de pareceres técnicos do DPF e da ANVISA:

Por fim, as razões maiores deste controle por parte da administração pública são especificamente coibir a utilização ilícita de substâncias psicotrópicas pela sociedade e combater o narcotráfico, motivações estas que poderão ser brilhantemente acolhidas pela ANVISA ${ }^{24}$.

Ressalto também a importância desta inclusão para que os Órgãos de Repressão a Entorpecentes consigam realizar o combate ao tráfico de drogas, visto que conforme a Lei $n^{0} 11.343 / 06$ classifica como drogas as substâncias entorpecentes, psicotrópicas, precursoras e outras sob controle especial, da Portaria SVS/MS no $344 / 98^{25}$.

Em diversos dos pareceres técnicos da ANVISA há manifesta preocupação para a utilização de "critérios equânimes para classificação de substâncias", embora não haja uma definição clara de quais seriam esses critérios.

Curiosamente, nos processos analisados houve duas tentativas de inclusão da substância nicotina (um dos principais componentes do cigarro de tabaco) nas listas de substâncias sob controle. A proposição, ex officio da própria ANVISA, não pretendia incluíla nas listas de substâncias de uso proscrito, mas sim na lista $C 1^{26}$ ("outras substâncias sob controle especial").

Na instrução para edição da Resolução de Diretoria Colegiada nํ 37/2012, afirma-se em parecer técnico:

Já a inclusão da nicotina na lista de substâncias controladas se faz necessário por ser uma molécula de significativa toxicidade e dependência, capaz de desencadear o processo neoplásico maligno principalmente nos pulmões e pâncreas. As doenças tabaco relacionadas matam 6 milhões de pessoas no mundo atualmente. O tabaco mata mais que a AIDS, a cocaína, o álcool, os suicídios e os acidentes de trânsito somados ${ }^{27}$.

Nessa ocasião, a Diretoria Colegiada não aprovou a inclusão da nicotina na lista C1:

\footnotetext{
24 Parecer Técnico oㅜ 003/2013-SEDQ/DIREN/CGPRE/DCOR do DPF/MJ

25 Processo Administrativo no 25351.563464/2013-13, fls. 4

${ }^{26}$ As substâncias da lista C1 não tem seu consumo proibido, mas sim controlado, estando sujeitas a Receita de Controle Especial em duas vias.

27 Parecer Técnico 008/2011-GPDTA/DIAGE/ANVISA
} 
[...] a GGIMP28 deverá fundamentar proposta de inclusão da nicotina na lista $\mathrm{C} 1$, inclusive avaliando se esta inclusão alcançará os objetivos desejados. Após os esclarecimentos deverá encaminhar o processo à procuradoria para ser realizada avaliação jurídica da proposta. O Diretor José Agenor registra que é favorável à proposição, que não possui dúvidas quanto à inclusão da nicotina na lista $\mathrm{C} 1$ ora proposta ${ }^{29}$.

Posteriormente, na instrução da Resolução de Diretoria Colegiada nº 06/2014, afirmase em relatório de instrução de proposição:

A nicotina é uma molécula com grande capacidade de causar dependência. Seu potencial aditivo é maior que o da cocaína, morfina e álcool. Da mesma forma que outras moléculas com capacidade aditiva, a nicotina possui propriedades que desencadeiam sensações prazerosas, que se traduzem na compulsão do consumo desta molécula e ainda síndrome de abstinência associada à privação ${ }^{30}$.

Ao final a resolução foi aprovada sem a inclusão da nicotina, com a informação de que será tratada em separado "tendo em vista a melhor avaliação do impacto da inclusão pela GGTAB ${ }^{31}$ e sua efetividade", sendo certo que até a última versão da Portaria $\mathrm{n}^{0}$ 344/1998 a nicotina não havia sido incluída no rol de substâncias sob controle e não havia análise conclusiva sobre esse assunto.

A afirmação de que o potencial aditivo e de dano à saúde da nicotina é superior ao de drogas consideradas ilícitas pode indicar a existência de certo incômodo institucional com a indefinição dos tais "critérios equânimes para classificação de substâncias". Ao contrário do que ocorreu nos demais processos analisados, no caso da nicotina não existe presunção em favor da proibição, mas sim favorável à liberalização irrestrita.

Apesar dos argumentos de saúde pública incisivos e temerários apresentados no parecer técnico, a ANVISA optou por não controlar preventivamente, reforçando a percepção de que argumentos de saúde pública tem pouca ou nenhuma importância para a classificação das substâncias quando comparados aos argumentos relacionados à segurança e combate ao narcotráfico.

28 Gerência-Geral de Inspeção, Monitoramento da Qualidade, Controle e Fiscalização de Insumos, Medicamentos e Produtos, Propaganda e Publicidade.

${ }^{29}$ Reunião Ordinária Pública da Diretoria Colegiada nº 19/2012.

30 Processo Administrativo 25351.563464/2013-13, fls. 3

31 Gerência-Geral de Produtos Derivados do Tabaco. 


\section{Conclusão}

A pesquisa demonstrou que o Brasil possuiu autonomia limitada para a classificação de drogas, tendo em vista que essa autonomia somente pode ser exercida no sentido de maior rigor da política de drogas comparativamente às disposições de direito internacional. Verificou-se que há discricionariedade no exercício do poder regulatório pela ANVISA quanto à inclusão de itens no rol de substâncias entorpecentes, substâncias psicotrópicas e plantas de uso proscrito no Brasil, não estando limitado ao conteúdo das listas das convenções internacionais sobre o tema e tampouco à existência de parâmetros no ordenamento jurídico interno.

Diante desse cenário, considerou-se pertinente a análise do trâmite dos processos administrativos e dos motivos considerados pela ANVISA para imposição das proibições, por meio das atualizações da Portaria SVS/MS no 344/1998 que complementam o sentido da norma penal em branco contida na Lei no 11.343/2006 (lei de drogas).

Quanto às substâncias em que não havia correspondência em listas das convenções internacionais, observou-se que as iniciativas dos processos foram do Departamento de Polícia Federal, do Ministério Público do Estado de São Paulo e da própria ANVISA ex officio, mas em geral relacionada à solicitação do Departamento de Polícia Federal.

Apesar de a ANVISA ser uma autarquia vinculada ao Ministério da Saúde, não se verificou a colaboração de especialistas da área de Saúde Mental, Álcool e outras Drogas. Esse fato reforça a percepção de que a questão das drogas deixou de ser tratada como um problema de saúde pública e tornou-se uma questão de segurança nacional, com o combate ao narcotráfico, conforme apontam especialistas críticos da política de guerra às drogas. (12) (22) (23)

Devido à influência assimétrica de grupos de interesse nesse processo, parece haver uma presunção que pende a favor da proibição, pois em geral trata-se de novas drogas cujos efeitos são pouco conhecidos e que há uma premência do tempo. O argumento de necessidade de combate ao narcotráfico é recorrente.

As práticas de accountability e transparência, nos processos de inclusão de substâncias na Portaria SVS/MS no 344/1998 analisados, restringiram-se à publicidade da deliberação em Reuniões Ordinárias Públicas da Diretoria Colegiada e à publicação dos normativos no Diário Oficial da União. Não foram realizadas consultas públicas, audiências 
públicas ou consultas às câmaras setoriais e técnicas, instrumentos postos à disposição da ANVISA e que propiciariam participação da sociedade, ampliação do debate e melhoria da qualidade da decisão.

A proibição do acesso a determinadas substâncias afeta todos na medida em que se restringe a liberdade de escolha, entretanto a sociedade não tem sido considerada pela ANVISA como interlocutora e parte interessada nesse processo. Para mudar essa realidade, é preciso que os tomadores de decisão percebam que não se trata de uma escolha apenas técnica, mas também política quanto aos seus pressupostos e suas implicações, embora os aspectos técnicos relacionados aos impactos das substâncias analisadas na saúde devam ser considerados.

Parece haver uma preocupação institucional de que os critérios técnicos sejam equânimes, mas é preciso que também sejam transparentes. A ANVISA dispõe de ferramentas que possibilitariam um debate mais amplo e clareza quanto aos fundamentos utilizados para a classificação e proibição de substâncias.

Por fim, pondera-se que a regulação da produção, comércio e consumo tem sido apontada por especialistas como uma solução para o problema da guerra às drogas (24) (25). Desse modo reveste-se de especial importância a necessidade de um processo regulatório que se coadune aos princípios do Estado Democrático de Direito.

\section{Referências}

1. Brasil. Ministério da Saúde. Portaria da Secretaria de Vigilância Sanitária no 344 de 12 de maio de 1998. Aprova o Regulamento Técnico sobre substâncias e medicamentos sujeitos a controle especial. Diário Oficial da União. 15 mai 1998.

2. Tribunal de Justiça do Distrito Federal e Territórios. 4a Vara de Entorpecentes do Distrito Federal. Ação Penal - Procedimento Ordinário 2013.01.1.076604-6. Distribuída em 31 mai 2013.

3. Pierry F. Juiz titular desautoriza substituto que liberou portador de maconha. O Globo. 30 jan 2014. [Acesso em 06 mar 2016] Disponível em http://oglobo.globo.com/brasil/juiztitular-desautoriza-substituto-que-liberou-portador-de-maconha-11452272.

4. Brasil. Ministério da Justiça, Departamento Penitenciário Nacional. Levantamento Nacional de Informações Penitenciárias - Junho de 2014. Brasília, 2014. 
5. Silva MB, Delduque MC. Patologização e penalização do uso de drogas: uma análise socioantropológica de proposições legislativas (2007-2010). Physis 25 jan-mar/2015, 25 (1): $231-250$

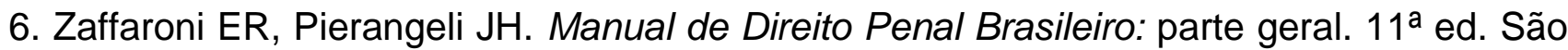
Paulo: Revista dos Tribunais; 2015.

7. Brasil. Lei 11.343 de 23 de agosto de 2006. Institui o Sistema Nacional de Políticas Públicas sobre Drogas - Sisnad; prescreve medidas para prevenção do uso indevido, atenção e reinserção social de usuários e dependentes de drogas; estabelece normas para repressão à produção não autorizada e ao tráfico ilícito de drogas; define crimes e dá outras providências. Diário Oficial da União. 24 ago 2006.

8. Brasil. Presidência da República. Decreto 5.912 de 27 de setembro de 2006. Regulamenta a Lei no 11.343, de 23 de agosto de 2006, que trata das políticas públicas sobre drogas e da instituição do Sistema Nacional de Políticas Públicas sobre Drogas SISNAD, e dá outras providências. Diário Oficial da União. 28 set 2006.

9. Brasil. Lei oㅜ 9.782, de 26 de janeiro de 1999. Define o Sistema Nacional de Vigilância Sanitária, cria a Agência Nacional de Vigilância Sanitária, e dá outras providências. Diário Oficial da União. 27 jan 1999.

10. Brasil. Decreto no 3.029, de 16 de abril de 1999. Aprova o Regulamento da Agência Nacional de Vigilância Sanitária, e dá outras providências. Diário Oficial da União. 19 abr 1999.

11. Brasil. Agência Nacional de Vigilância Sanitária. Resolução da Diretoria Colegiada no 29, de 21 de julho de 2015. Aprova e promulga o Regimento Interno da Agência Nacional de Vigilância Sanitária - ANVISA e dá outras providências. Diário Oficial da União. 23 jul 2015.

12. Lima RCC. Uma história das drogas e seu proibicionismo transnacional: relações Brasil - Estados Unidos e os organismos internacionais. [Tese]. Rio de Janeiro: Programa de Pós-graduação em Serviço Social, Universidade Federal do Rio de Janeiro; 2009.

13. Organização das Nações Unidas. Convenção Única sobre Entorpecentes, 1961. [Acesso em 10 jun 2016]. Disponível em https://www.unodc.org/pdf/convention_1961_en.pdf

14. Organização das Nações Unidas. Convenção sobre Substâncias Psicotrópicas, 1971. [Acesso em 10 jun 2016]. Disponível em https://www.unodc.org/pdf/convention_1971_en.pdf

15. Organização das Nações Unidas. Convenção Contra o Tráfico llícito de Entorpecentes e Substâncias Psicotrópicas, 1988. [Acesso em 10 jun 2016]. Disponível em https://www.unodc.org/pdf/convention_1988_es.pdf 
16. Labate BC, Araújo WS, organizadores. O Uso Ritual da Ayahuasca. Campinas, Mercado de Letras, São Paulo, Fapesp; 2002.

17. Meirelles HL. Direito Administrativo Brasileiro. 25르 Ed. São Paulo: Malheiros; 2000.

18. Aranha MI. Manual de Direito Regulatório (Fundamentos de Direito Regulatório). $2^{2}$ ed. Coleford, UK: Laccademia Publishing; 2014.

19. Cruz V. Transparência e accountability na regulação da vigilância sanitária no Brasil. Revista Direito Sanitário, nov/2009-fev/2010, 10 (3): 90-114.

20. Souza C. Políticas públicas: uma revisão da literatura. Sociologias, 2006 jul/dez 16: 2045.

21. Brasil. Lei oㅜ 12.527, de 18 de novembro de 2011. Regula o acesso a informações previsto no inciso XXXIII do art. $5^{\circ}$, no inciso II do $\S 3^{\circ}$ do art. 37 e no $\S 2^{\circ}$ do art. 216 da Constituição Federal; altera a Lei no 8.112, de 11 de dezembro de 1990; revoga a Lei no 11.111, de 5 de maio de 2005, e dispositivos da Lei no 8.159, de 8 de janeiro de 1991; e dá outras providências. Diário Oficial da União. 18 nov 2011.

22. Del Olmo R. Drogas: distorsiones y realidades, Nueva Sociedad, jul-ago 1989 (102): 81-93.

23. Carvalho S. A atual política brasileira de drogas: os efeitos do processo eleitoral de 1998. Revista Brasileira de Ciências Criminais. 2001 (34): 129-146.

24. Comissão Global de Políticas sobre Drogas. Sob controle: caminhos para políticas de drogas que funcionam. Relatório. 2014. Disponível em http://www.gcdpsummary2014.com/bem-vindo/\#foreword-from-the-chair-pt

25. Karam ML. Drogas: legislação brasileira e violação aos direitos fundamentais. LEAP Brasil. Abril, 2010. Disponível em <http://www.leapbrasil.com.br/textos> Acesso em 25agosto-2014.

Recebido em: 14/6/2016

Aprovado em: 19/9/2016

Como citar este artigo:

Soares MK, Zackseski CM. Proibicionismo e poder regulatório: uma pesquisa documental sobre o processo administrativo de classificação das drogas. Revista Cadernos Ibero-Americanos de Direito Sanitário. 2016 jul./set, 5(3):135-156. 